\title{
Design-based research as an innovation approach in the construction and evaluation of IBSME
}

\author{
Josef Trna and Eva Trnova \\ Faculty of Education, Masaryk University, Brno, Czech Republic \\ For correspondence: trna@ped.muni.cz
}

\begin{abstract}
Inquiry-based science and mathematics education (hereinafter IBSME) is a current, supported and implemented teaching/learning method in science and mathematics education. IBSME aims to increase the self-efficacy of teachers in taking ownership of more effective ways of science and mathematics teaching and learning. Students should benefit from IBSME in order to help their motivation and understanding of science and mathematics. An important task is to develop methods for the construction and evaluation of IBSME. We confirmed that design-based research is the appropriate method. Design-based research is a new trend in educational research. This method can be described as a cycle: analysis of a practical problem, development (construction) of solutions, evaluation and testing of solutions in practice and reflection and production of new design principles. Our research outcomes on the use of design-based research in the construction and evaluation of IBSME especially by teachers are presented. This study has been created within the Seventh Framework Programme European project PROFILES, which supports teachers in their use of IBSME.
\end{abstract}

Keywords: construction, design-based research, evaluation, IBSME

\section{Introduction}

Science and mathematics education is an essential part of each individual's personality. This education gives answers to many fundamental issues of the day and allows the practical problems of everyday life to be solved. It has also other objectives such as the development of critical thinking, development of positive attitudes towards the environment, to society and to themselves. In meeting these fundamental objectives science and mathematics education is irreplaceable. This proposition in today's postmodern era is often questioned, but their validity has been, is and will be unquestionable and will not have to be re-certified.

Science and mathematics education is very difficult, especially in its exactness and use of mathematics as a means of communication. Good mastery of this communication and discourse requires accelerated learning and long-term systematic training for students. Many students, however, reject this difficult learning work with the use of false rejection reasons about its uselessness for their life. This paradox is often supported by parents who want comfort for their children and excuse their failures based on the low learning efforts.

Science educators in many countries face a problematic decline in the study of science, mathematics and technology (OECD, 2006). One of the factors leading to this stage is considered the unsuitable outdated method of teaching/learning science in schools (Rocard et al., 2007). Only $15 \%$ of European students are satisfied with the quality of science teaching in schools. Students consider science to be very difficult and even though they believe the contents of science are important for society, they consider them unnecessary in their everyday life.

Teachers fall under uncomfortable pressure, which they seek to limit by reducing the demands on the level of education. This is the wrong way, which should be avoided for the benefit of parents and children. The solution is to search for innovative teaching/learning methods, which include IBSME. 


\section{Rationale}

Defining IBSME is given sufficient attention in the literature. However, it is necessary to describe the essential characteristics of design-based research. Within science and mathematics education research and development is carried out focussed mainly namely on the sphere of application, including innovation. An analogous situation is found in technical disciplines, where the design approach has a significant position. The core of the design approach in research is orientation towards the creation of a new product which brings about the solution of problems that so far have been only partially solved and the relevant tools and methods are only in their infancy. The design approach has been applied in a whole range of research areas during its development and practical application. The design approach is interdisciplinary and integrative. With the use of this approach we may successfully describe and research the design process, which has been graphically described in the Järvinnen (2004) model (Fig. 1).

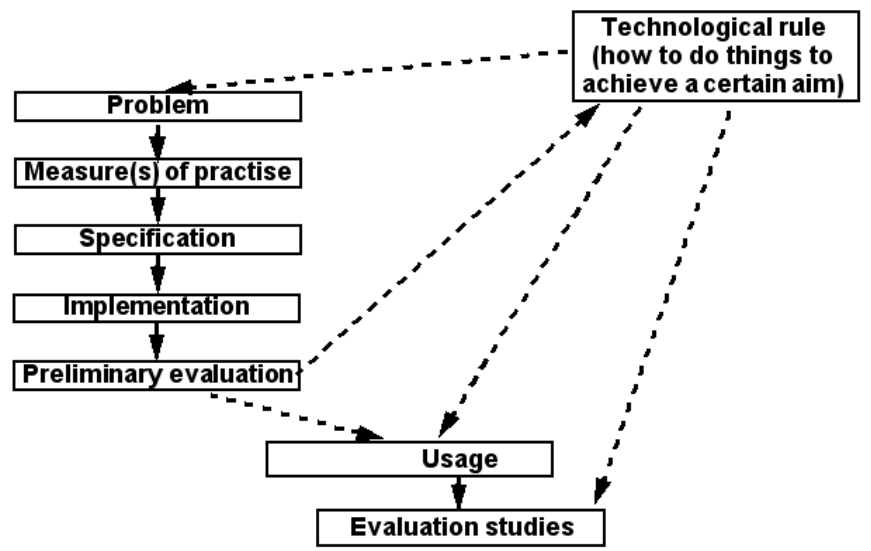

Figure 1. Model of design process (Järvinnen, 2004)

The design process consists of elements and links among them. According to Järvinnen (2004), the technological rule or design rule is the input or output of the research. The sequence from the problem to evaluation studies corresponds to the design method, which is the development from design to product. This sequence includes the product creation. It is, therefore, a development stage. Proper design process research may be focused mainly namely on the links marked with broken lines (Fig. 1). Introduction of the design approach into science and mathematics education leads to the establishment of a new type of research, which we call design-based research (hereinafter DBR). The complexity of growing findings and practical issues in education requires team cooperation in DBR. In this team there may be a couple of researchers: a researcher in science and mathematics education and an experienced teacher from a school setting.

DBR as development research differs from other types of educational research. We can compare DBR research as development research and empirical research, which was compiled by Reeves (2006) (Fig. 2).

A great advantage of DBR is its systematic interconnection with practice. The principle of DBR is the close cooperation between experts and teachers. 

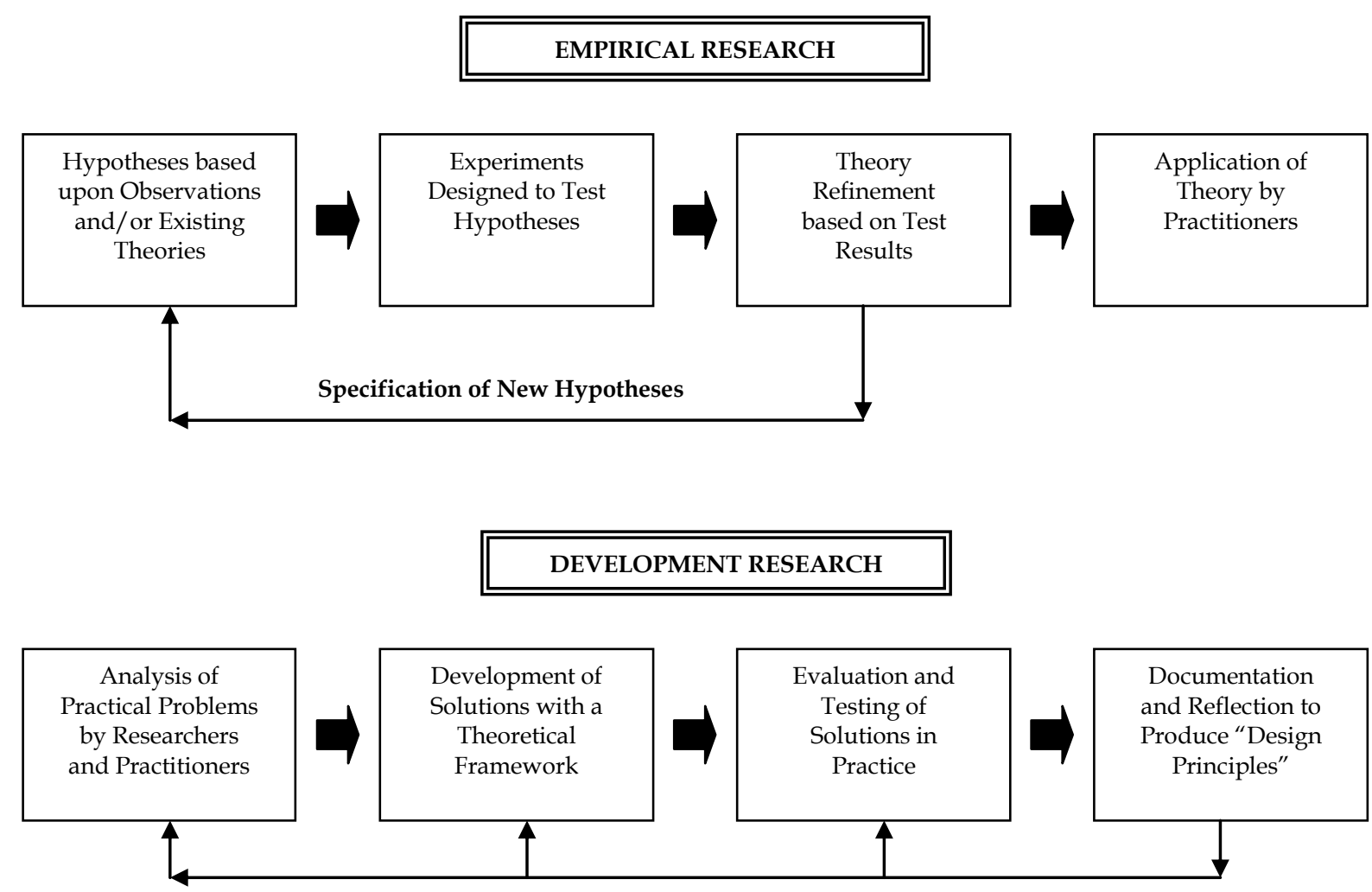

Refinement of Problems, Solutions, and Methods

Figure 2. Empirical and development approaches to educational research (Reeves, 2006)

\section{Research question and methods}

The presented DBR is a research method in science and mathematics education, but also has a strong link to educational practice. Therefore we aimed our research topic towards the support of teacher professional competences in the frame of continuous professional development (hereinafter CPD). DBR can be implemented in IBSME from a teacher's point of view in two ways:

(a) the teacher is a member of the IBMSE research team using DBR

(b) the teacher follows a special IBSME construction and evaluation method based on the stages of DBR

The procedure (a) is suitable only for a small number of excellent teachers, but the procedure (b) can be used collectively in the frame of CPD. Our research question is therefore as follows:

What form might the construction and evaluation of IBSME have based on DBR as a support of teacher CPD?

The research method that has helped us to answer this question is DBR. Our research thus acquired an interesting design, as the research method used is partially applied to itself.

\section{Results and discussion}

According to our research (Trna and Trnova, 2010b) and experience, we have discovered and modified four IBSME construction and evaluation methods (forms) of implementation of DBR components:

- Analysis of practical educational problems in IBSME

Teachers identify the existing educational problems in IBSME while using the methods of observation, questionnaires, analyses of students' works, interviews, etc. 
- Construction (development) of suitable IBSME components with a theoretical framework

Teachers develop IBSE teaching/learning methods and tools in order to identify educational problems in IBSME. They demonstrate externally the form of pedagogical content knowledge (hereinafter PCK). A frequent weakness of this development is the failure to clarify the theoretical framework of their products. That is why this teacher method requires organization and professional management of teacher training in CPD.

- Practical testing and evaluation of suitable IBSME components

Teachers are the authorised and true implementers and evaluators of innovated teaching /learning methods (like IBSME) created by experts (Trna and Trnova, 2010a). Teachers may also work as participants in research teams, as co-authors of text books, instruments, etc.

- Action research of suitable IBSME components

The action research may be perceived as a part of the DBR. In the last few years, action research has been implemented into teachers' daily practice more often. Teachers use the action research cycle for verification of innovative IBSME ideas. Thus, there occurs a significant development of PCK and ownership of each teacher who uses action research.

The first three methods directly correspond to the first three stages of DBS. These stages may exist relatively independently and they also work in this way in practice. After this comes the comprehensive action research.

As an example of DBR implementation in teacher construction and evaluation of IBSME we present the method Practical testing and evaluation of suitable IBSME components. Teachers were asked to test and evaluate the IBSME module, whose theme was "As scientists discover nature through their senses". This IBSE module describes a scientific approach to natural phenomena in the form of the basic methods of scientific work: observation and description. This IBSE module provides a set of methods of scientific work with which students can explore the world of science: experimenting, modelling, discussing of phenomena, conceptions of phenomena etc. Students are confronted with many scientific phenomena which they have to observe simply by using all the senses. This IBSME module was developed within the project PROFILES and contains many simple experiments. These experiments show how we use the senses to inquire into nature. A theoretical framework was the theory of hands-on and minds-on experiments (Haury and Rillero, 1994). A teacher group of fifteen in-service lower-secondary science teachers were asked in 2013 to test and to evaluate a series of simple experiments in the frame of testing and evaluation the whole of the IBSME module. We give two simple experiments from this IBSME module as an example:

Experiment 1: Place a coin on the moist neck of an empty glass bottle (Fig. 3). Take the bottle into your hands thus you will warm the air in the bottle (we recommend cooling the air in the bottle beforehand by a flow of cold water). After a moment the coin will start to jump up and down almost periodically.

Explanation: the heated air in the bottle increases its volume and pressure. Such strength of the heated air will lift up the coin.

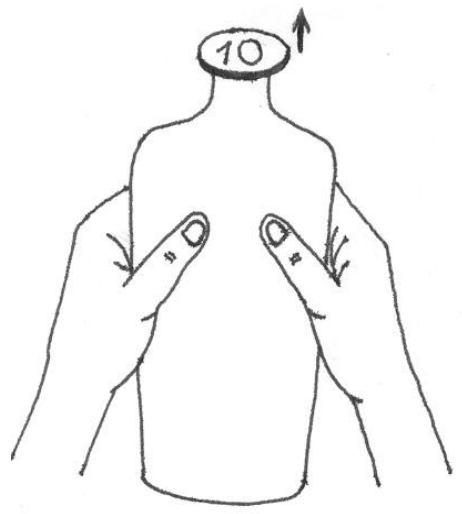

Figure 3. Thermal expansivity of air 
Experiment 2: Place a coin on the bottom of a non-transparent mug so that you cannot see it from the side (Fig. 4). After you pour water into the mug the coin will appear without you changing the angle of view.

Explanation: The surface of water in the mug will become a boundary of two different optical environments in which there will occur a refraction of light beams coming out of the coin - refraction from perpendicular - and in this way these beams get into the eye and we can see the coin.

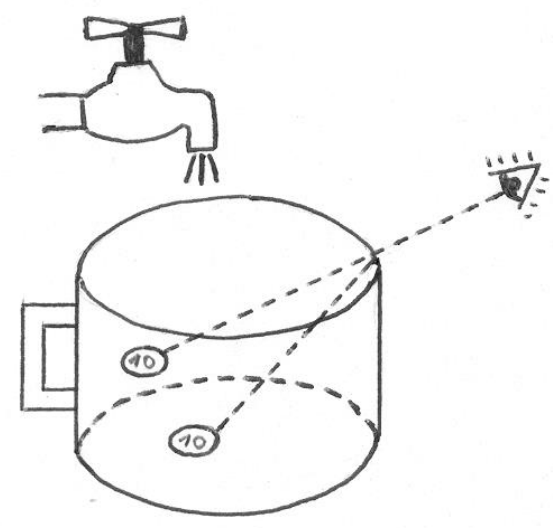

Figure 4. Refraction of light

These simple experiments evidence the use of human senses in observing, experimenting and measuring in science. Feedback verification of the efficiency of the implementation of DBR methods in IBSME during in-service lower-secondary science teachers' testing and evaluation was carried out by a questionnaire. This questionnaire was applied to teachers who participated in the testing of experiments. The frequencies of their selected answers can be seen in Tab. 1.

Table 1. Teacher questionnaire answers.

\begin{tabular}{|c|c|c|}
\hline & Questions from the teacher questionnaire & $\begin{array}{c}\text { Frequency of } \\
\text { answers: } \\
\text { YES }\end{array}$ \\
\hline 1 & Were you interested in the testing and evaluation of experiments? & $78 \%$ \\
\hline 2 & Will you use some of these experiments in your future teaching? & $81 \%$ \\
\hline 3 & Will you develop your own experiments in the future? & $33 \%$ \\
\hline 4 & $\begin{array}{l}\text { Do you feel a shift in your competency to teach science after you completed } \\
\text { the testing and evaluation course of IBSME? }\end{array}$ & $42 \%$ \\
\hline
\end{tabular}

\section{Conclusions}

We have modified a set of methods for the creation and evaluation of IBSME that are based on the stages of DBR. These methods are: (1) analysis of practical educational problems in IBSME, (2) construction (development) of suitable IBSME components with a theoretical framework, (3) practical testing and evaluation of suitable IBSME components, and (4) action research of suitable IBSME components. We have verified the effectiveness of these methods in practice.

The above presented construction and evaluation methods based on DBR implemented in IBSME aimed at supporting teacher CPD anticipate experienced teachers. These methods, therefore, are suitable namely for in-service science teachers. It is clear that these methods may be used also in preservice science teacher training. We inform these student-teacher candidates of the principles and function of DBR in science education, especially in IBSME. 


\section{Acknowledgements}

The study was initiated within the project the project PROFILES: Professional Reflection-Oriented Focus on Inquiry-based Learning and Education though Science (FP7-SCIENCE-IN-SOCIETY-2010-1, 266589).

\section{References}

Haury, D. L. and Rillero, P. (1994). Perspectives of Hands-On Science Teaching. Columbus, Ohio: ERIC-CSMEE. Järvinen, P. (2004). On Research Methods. Tampere, Finland: Opinpajan Kirja.

OECD. (2006). Evolution of Student Interest in Science and Technology Studies - Policy Report. Retrieved January 15, 2012, from Global Science Forum web: http://www.oecd.org/dataoecd/16/30/36645825.pdf (accessed January 2014)

Reeves, T. C. (2006). Design research from the technology perspective. In J. V. Akker, K. Gravemeijer, S. McKenney, \& N. Nieveen (Eds.), Educational design research. (pp. 86-109). London, UK: Routledge.

Rocard, M., Cesrmley, P., Jorde, D., Lenzen, D., Walberg-Herniksson, H. and Hemmo, V. (2007). Science education NOW: A Renewed Pedagogy for the Future of Europe. Brussels, Belgium: Office for Official Publications of the European Communities. Retrieved January 15, 2012, from EU: http:/ /ec.europa.eu/research/sciencesociety/document_library/pdf_06/report-rocard-on-science-education_en.pdf (accessed January 2014)

Trna, J. and Trnova, E. (2010a). ICT-based collaborative action research in science education. Proceedings of Word conference IMSCI'10. The 4th International Multi-Conference on Society, Cybernetics and Informatics. Volume I., International Institute of Informatics and Systematics, Orlando, USA, 68-70.

Trna, J. and Trnova, E. (2010b). Implementation of design-based research methodology into science teachers' training. International Journal on New Trends in Education and Their Implications, 2(4), 19-28. 